\title{
PENGARUH KEPEMIMPINAN, MOTIVASI, DAN IKLIM ORGANISASI TERHADAP KINERJA KARYAWAN DI WARUNG MINA PEGUYANGAN DENPASAR
}

\author{
I Kadek Adnyana Dwi Putra ${ }^{1}$ \\ I Gst Bagus Honor Satrya ${ }^{2}$
}

${ }^{1,2}$ Fakultas Ekonomi dan Bisnis Universitas Udayana (Unud), Bali, Indonesia e-mail: adnyanaputraputra@gmail.com

\begin{abstract}
ABSTRAK
Sumber daya manusia (SDM) hal yang pentingdalam suatu organisasi, adanya perlakuan yang adil dan memuaskan pada SDM pada organisasi tersebut dapatmenciptakan kinerja yang maksimal oleh karyawan di dalam organisasi. Tujuan penelitian ini adalah untuk mengetahui pengaruh kepemimpinan, motivasi, dan iklim organisasi terhadap kinerja karyawan. Jumlahsampel yang di gunakan berjumlah 44 responden dengan menggunakan metode probabilty sampling dengan teknik random sampling.Pengumpulan data dilakukan melalui wawancara, observasi dan kuesioner. Teknik analisis yang digunakan adalah regresi linier berganda. Berdasarkan hasil analisis diperoleh kepemimpinanberpengaruh positif dan signifikan terhadap kinerja karyawan, motivasi berpengaruh positif dan signifikan terhadap kinerja karyawan, dan iklim organisasi berpengaruh positif dan signifikan terhadap kinerja karyawan. Hal ini menunjukan apabila kepemimpinan, motivasi, dan ikilm organisasi di Warung Mina Peguyangan baik, maka kinerja karyawan di Warung Mina Peguyangan juga meningkat.
\end{abstract}

Kata kunci: kepemimpinan, motivasi, iklim organisai, kinerja karyawan

\begin{abstract}
Human resources (HR) matters are important in an organization, the existence of fair and satisfying treatment in $H R$ in the organization can create maximum performanceof employees in the organization. The purpose of this study was to determine the effect of leadership, motivation, and organizational climate on employee performance. The number of samples used amounted to 44 respondents using probabilty sampling method with random sampling technique. The data collection is done through interviews, observations and questionnaires. The analysis technique used is a multiple linear regression. Based on the results of the analysis obtained leadership has a positive and significant effect on employee performance, motivation has a positive and significant effect on employee performance, and the organizational climate has a positive and significant effect on employee performance. This shows that if the leadership, motivation, and organization at Warung Mina Peguyangan are good, then the performance of employees at Warung Mina Peguyangan also increases.
\end{abstract}

Keywords: leadership, motivation, organizational climate, employee performanc 


\section{PENDAHULUAN}

Sumber daya manusia merupakan salah satu bagian penting perusahaan yang diperlukan dalam menunjang setiap kegiatan perusahaan. Keseluruhan kegiatan perusahaan bergantung pada SDM yang ada, sehingga dapat dikatakan bahwa sumber daya manusia menjadi penentu berhasil atau tidaknya sebuah perusahaan mencapai tujuannya. Tanpa adanya SDM, aktivitas perusahaan tidak akan terjadi (Hasibuan, 2008:12).

Setiap organisasi atau perusahaan pastinya memiliki tujuan, baik tujuan jangka panjang maupun pendek yang ingin diraih darikegiatan yang dilakukannya. Agar tujuan organisasi dapat tercapai, dibutuhkan pengelolaan danperencanaan SDM yang baik. Menurut Leriana (2016), Perlakuan yang adil dan memuaskan kepada SDM yang bekerja dalam organisasi mampu menciptakan tingkat kinerja yang maksimal.

Era yang moderen ini, organisasi dituntut mempunyai mental berkompetisi sehingga mampu bertahan dalam persaingan global (Sudarmanto,2009:1). Strategi agar mampu berkompetisi yaitu dengan meningkatkan kapasitas organisasi dan SDM yang dimiliki (Wijayanti, 2012).

Penelitian ini di lakukan di Warung Mina Peguyangan Denpasar Bali yang berlokasi di Jalan Astasura No.99 Peguyangan di Denpasar Bali. Pada mulanya warung mina tersebut hanyalah kolam ikan biasa yang pemiliknya Bapak I Wayan Setiawan. Awalanya kolam ikan ini hanyalah sebuah tempat untuk menyalurkan hobi masyarakat setempat yang di jadikan untuk kegiatan atau aktivitas memancing. Setelah beliau pensiun dari pekerjaannya sebagai petinju jelas tidak 
ada biaya tambahan yang menghidupi beliau dan sekeluarga. Beliau akhirnya mempunyai tekad untuk menjadikan kolam ikan ini sebagai usaha kecil-kecilan. Masyarakat yang memancing di kolam ikan tersebut yang berhasil mendapatkan ikan diperbolehkan untuk membakar atau memasak ikan tangkapannya dengan membayar biaya tambahan.

Setelah usaha tersebut terbilang berhasil beliaupun mulai membuat atau menciptakan inovasi baru guna lebih meningkatkan usahanya tersebut. Akhirnya beliau bertekad mendirikan restoran atau warung makan disamping kolam ikannya tersebut. Untuk mewujudkan keinginannya tersebut beliau meminjam uang untuk membangun sebuah restoran di daerah Peguyangan dengan nama Warung Mina. Warung Mina pertama kali didirikan di daerah Peguyangan tepatnya pada tahun 1994. Saat ini Warung Mina Peguyangan memiliki total jumlah karyawan sebanyak 44 orang. dapat dilihat pada Tabel 1 sebagai berikut.

Tabel 1.

Data Jumlah Karyawan Warung Mina Peguyangan Di Denpasar 2018

\begin{tabular}{ccc}
\hline No. & \multicolumn{1}{c}{ Department } & Jumlah Karyawan \\
\hline 1. & Manager & 1 \\
2. & Accounting & 1 \\
3. & Team Service & 17 \\
5. & Team Bartender & 4 \\
6. & Team Kitchen & 16 \\
7. & Team Security & 5 \\
\multicolumn{2}{c}{ Total : } & 44 \\
\hline Sumber: Supervisor Servis Warung Mina Peguyangan Denpasar Bali, 2018.
\end{tabular}

Setelah di lakukannya pra-riset yang di lakukan di Wrung Mina Peguyangan dengan melibatkan 10 (sepuluh) responden yang di ambil secara acak, ditemukan adanya indikasi yang menunjukan masih ada karyawan yang tidak bisa berkerja tim dengan baik, salah satu karyawan pada department service dan department security mengabaikan pekerjaannya dan berbicara di saat jam kerja, sedangkan 
departmentservice sedang melakukan tugasnya untuk menyiapkan tempat hidangan kepada tamu yang telah memesan tempat di Restoran Warung Mina Peguyangan.

Ketidak cocokan dan ketidak nyamanan berkerja dengan tim dan karyawan lainnya, yang mengakibatkan kinerja pada department security dan department service menjadi kurang optimal sehinga merugikan tamu yang telah memesan tempat di Restoran Warung Mina Peguyangan, karena salah satu karyawan pada departmentservice terlambat dalam menyiapkan dan membersihkan tempat untuk tamu yang telah memesan di Warung Mina Peguyangan, yang mengakibatkan kerja tim tidak kosisten dengan deskripsi kerja. Data tersebut didapatkan dari hasil wawancara oleh supervisor service dan beberapa karyawan Warung Mina Peguyangan.

Suatu proses yang dimiliki dari seorang pemimpin dalam memengaruhi sikap, nilai-nilai dan prilaku orang lain merupakan pengertian dari kepemimpinan. Setelah dilakukanya pra-riset yang dilakukanya di Warung Mina Peguyangan dengan beberapa karyawan,terdapat beberapa permasalahan pada pemimpin Warung Mina, yaitu kurangnya petegasan dalam menghadapi karyawan di saat jam kerja dan kurangnya kemampuan analitis. Kemampuan analitis yaitu kemampuan menganalisa situasi yang di hadapi secara teliti, matang, dan mantap, merupakan prasyarat untuk kesuksesan seorang pemimpin, dari kurangnya ketegasan dan kemampuan analitis tersebut yang mengakibatkan karyawan mengabaikan pekerjaannya di saat jam kerja, contohnya salah satu karyawan pada 
departmentservice berbicara dengan department security dan mengabaian pekerjaannya yang mengakibatkan kerja tim tidak kosisten dengan deskripsi kerja.

Motivasi merupakan bagian penting yang di perlukan oleh kinerja karyawan di perusahaan,karena motivasi diharapkan mampu memberikan semangat bagi setiap karyawan agar antusiasbekerja keras untuk mencapai kinerja produktivitas yang tinggi. Setelah dilakukannya wawancara di Warung Mina Peguyangan terdapat permasalahan yaitu kinerja karyawan pada Warung Mina Peguyangan masih kurang optimal, yaitu kurangnya kebutuhan sosial, kebutuhan sosial adalah keserasian dan keterpaduan antara tujuan kelompok informal dengan organisasi yang dapat menjadi aset besar demi meningkatkan produktivitas perusahaan, contohnya kinerja karyawan pada department service menjadi kurang optimal dalam menyiapkan tempat untuk tamu, karena salah satu karyawan pada departmentservice mengabaikan pekerjaanya, yang mengakibatkan kinerja pada department service menjadi kurang optimal sehinga merugikan tamu yang telah memesan tempat di Restoran Warung Mina Peguyangan, karena salah satu karyawan pada departmentservice terlambat dalam menyiapkan dan membersihkan tempat untuk tamu yang telah memesan tempat di Warung Mina Peguyangan, yang mengakibatkan kerja tim tidak kosisten dengan deskripsi kerja.

Iklim organisasi adalah lingkungan internal organisasi, yang mempengaruhi peraktik dan kebijakan SDM yang diterima oleh anggota organisasi. Setelah dilakukannya wawancara di Warung Mina peguyangan terdapat permasalahan yaitu salah satu karyawan pada department service dan department security mengabaikan pekerjaannya dan berbicara di saat jam kerja, sedangkan 
departmentservice sedang melakukan tugasnya, untuk menyiapkan tempat hidangan kepada tamu yang telah memesan tempat di Warung Mina Peguyangan yang mengakibatkan ketidak cocokan dan ketidak nyamanan berkerja tim dengan karyawan lainnya yang mengakibatkan kinerja pada department security dan department service menjadi kurang optimal yang mengakibatkan kerja tim tidak kosisten dengan deskripsi kerja. Data tersebut didapatkan dari hasil wawancara oleh supervisor service dan beberapa karyawan Warung Mina Peguyangan.

Fenomena tersebut terjadi akibat pihak restoran yaitu pimpinan Warung Mina Peguyangan kurangnya pengawasan di saat jam kerja pada saat karyawan bekerja. Apabila SDM dalam perusahaan dapat bekerja dengan efektif, maka perusahaan pun mampu berkembang efektif, dengan kata lain kelangsungan hidup perusahaan ditentukan dari kinerja karyawan (Leriana, 2016).

Masalah-masalah pada Warung Mina Peguyangan seperti kerja tim yang kurang baik masih belum bisa teratasi, maka resikonya karyawan-karyawan yang bekerja di Restoran Warung Mina Peguyangan mulai tidak nyaman bekerja dengan tim serta dengan rekan kerjanya, dan mengakibatkan produktifitas menjadi tidak kosisten dengan deskripsi kerja yang di karenakan oleh karyawan yang tidak bisa bekerja tim dengan baik oleh timnya sendiri. Karyawan yang tidak nyaman bekerja di timnya sendiri, mengakibatkan karyawan tersebut berhenti bekerja sehingga merugikan Warung Mina Peguyangan. Contohnya permasalahan ditahun 2016 dan di tahun 2017 adanya perbedaan jumlah karyawan yang mengundurkan diri dari Warung Mina Peguyangan. Jumlah karyawan yang mengunduran diri pada tahun 2016 berjumlah 0 (nol), dari keseluruhan jumlah karyawan berjumlah 
49 orang sedangkan pada tahun 2017 terdapat jumlah karayawan yang mengundurkan diri berjumlah 15 orang, dari keseluruhan jumlah karyawan berjumlah 49 orang. Dari data yang dapatkan dari hasil wawancara di Warung Mina Peguyangan jumlah pengunduran diri yang paling tinggi yaitu di tahun 2017 yang berjumlah 15 orang karyawan, setelah di lakukannyan wawancara di Warung Mina Peguyangan, permasalah yang mempengaruhi karyawan pada Warung Mina Peguyangan yang mengundurkan diri yaitu, motivasi dan iklim organisasi.

Motivasi penting ,karenamotivasi dapat menimbulkan sikap antusias dalam bekerja setiap karyawan untuk mencapai kinerja produktivitas yang tinggi. Contohnya kinerja karyawan pada Warung Mina Peguyangan masih kurang optimal dikarenakan kurangnya kebutuhan sosial, kebutuhan sosial adalah keserasian dan keterpaduan antara tujuan kelompok informal dengan organisasi yang dapat menjadi aset besar demi meningkatkan produktivitas perusahaan, contohnya kinerja karyawan pada department service menjadi kurang optimal dalam menyiapkan tempat untuk tamu, karena salah satu karyawan pada departmentservice mengabaikan pekerjaanya, yang mengakibatkan kinerja pada department service menjadi kurang optimal sehingga merugikan tamu yang telah memesan tempat di Restoran Warung Mina Peguyangan, karena salah satu karyawan pada departmentservice terlambat dalam menyiapkan dan membersihkan tempat untuk tamu yang telah memesan tempat di Warung Mina Peguyangan, yang mengakibatkan kerja tim tidak kosisten dengan deskripsi kerja.

Lingkungan organisasi, yang memengaruhi praktik dan kebijakan SDM yang diterima oleh anggota organisasi merupakan pengertian dari Iklim 
organisasi. Contohnya salah satu karyawan pada department service dan department security mengabaikan pekerjaannya dan berbicara di saat jam kerja, sedangkan departmentservice sedang melakukan tugasnya, untuk menyiapkan tempat hidangan kepada tamu yang telah memesan tempat di Warung Mina Peguyangan, yang mengakibatkan ketidak cocokan dan ketidak nyamanan berkerja tim dengan karyawan lainnya, yang mengakibatkan kinerja pada department security dan department service menjadi kurang optimal yang mengakibatkan kerja tim tidak kosisten dengan deskripsi kerja. Data tersebut didapatkan dari hasil wawancara oleh supervisor service dan beberapa karyawan Warung Mina Peguyangan.

Fenomena tersebut juga dikatakan sebagai perputaran (turnover) adalah berhentinya seorang karyawan dari tempat bekerja secara sukarela atau pindah kerja dari tempat kerja sebelumnya ke tempat kerja lain (Lisan, dkk., 2016). Atau bisa disebut juga dengan "Turnover Intention" (keinginan berpindah) karyawan yang tinggi akan membawa pengaruh yang kurang baik terhadap organisasi, baik dari segi biaya maupun dari segi hilangnya waktu dan kesempatan untuk memanfaatkan peluang (Ratna dkk., 2015).

Untuk meningkatkan produktifitas kerja karyawan pada Warung Mina Peguyangan peran pimpinan dalam organisasi menjadi tanggung jawab oleh pimpinan untuk selalu berusaha membina tingkah laku serta memperhitungkan tingkah laku bawahan. Kepemimpinan yang baik serta komunikasi yang lancar merupakan faktor yang mempengaruhi kinerja karyawan. Kualitas, disiplin dan kreativitas merupakan modal utama yang harus dimiliki para karyawan dalam 
I Kadek Adnyana Dwi Putra, Pengaruh Kepemimpinan...

menunjukkan kinerjanya. Dari alasan tersebut perusahaan membutuhkan sosok pemimpin yang mampu memotivasi, mengkoordinasi orang-orang atau karyawan ke dalam kelompok kerja serta mengintegrasikan mereka ke dalam situasi atau iklim kerja yang solid dan harmonis guna mencapai tujuan bersama (Kiswanto, 2010).

Motivasi juga memilik peran penting dalam meningkatkan kinerja dan kepuasan kerja karyawan dapat ditentukan oleh faktor lain seperti iklim organisasi. Iklim Organisasi adalah persepsi anggota organisasi dan yang secara tetap berhubungan dengan organisasi mengenai yang terjadi di lingkungan internal organisasi secara rutin (Wirawan, 2008:122). Selain itu peran iklim organisasi juga penting di dalam kinerja karyawan karena iklim organisasi secara objektif eksis terjadi di setiap organisasi dan mempengaruhi perilaku anggota organisasi, tetapi hanya dapat di ukur secara tidak langsung melalui persepsi anggota organisasi (Wirawan, $2008: 124)$.

Alasan peneliti memilih Warung Mina Peguyangan sebagai lokasi penelitian adalah karena peneliti ingin memfokuskan pada satu objek penelitian yaitu di Restoran Warung Mina Peguyangan dan setelah dilakukannya pra-riset ditemukan adanya indikasi yang menunjukan masih ada karyawan yang tidak bisa berkerja tim dengan baik, salah satu karyawan pada department service dan department security mengabaikan pekerjaannya dan berbicara di saat jam kerja, sedangkan departmentservice sedang melakukan tugasnya untuk menyiapkan tempat hidangan kepada tamu yang telah memesan tempat di Restoran Warung Mina Peguyangan. 
Ketidak cocokan dan ketidak nyamanan berkerja dengan tim dan karyawan lainnya, yang mengakibatkan kinerja pada department security dan department service menjadi kurang optimal sehinga merugikan tamu yang telah memesan tempat di Restoran Warung Mina Peguyangan, karena salah satu karyawan pada departmentservice terlambat dalam menyiapkan dan membersihkan tempat untuk tamu yang telah memesan temapat di Warung Mina Peguyangan, yang mengakibatkan kerja tim tidak kosisten dengan deskripsi kerja. Data tersebut didapatkan dari hasil wawancara oleh supervisor service dan beberapa karyawan Warung Mina Peguyangan.

Berdasarkan uraian di atas beserta data-data yang didapatkan dari wawancara dapat di ketahui bahwa kinerja karyawan di Warung Mina Peguyangan masih belum optimal. Maka dalam penelitian ini bertujuan untuk mengukur kinerja karyawan terhadap kepemimpinan, motivasi dan iklim organisasi. Berdasarkan uraian di atas maka dapat ditarik judul pengaruh kepemimpinan, motivasi, dan iklim organisasi terhadap kinerja karyawan di Warung Mina Peguyangan Denpasar Bali Indonesia.

Berdasarkan permasalahan yang telah diuraikan sebelumnya, rumusan masalah penelitian adalah Bagaimana pengaruh kepemimpinan, iklim organisasi dan motivasi secara parsial pada kenerja karyawan di Warung Mina Peguyangan. Berdasarkan rumusan masalah yang telah disampaikan, maka yang menjadi tujuan dari penelitian ini adalah untuk mengetahui bagaimana pengaruh kepemimpinan, motivasi dan iklim organisasi terhadap kenerja karyawan di Warung Mina Peguyangan Denpasar. Adapun kegunaan penelitan dalam penelitian ini yaitu : 
Kegunaan secara teoritis dari hasil penelitian ini diharapkan dapat memperjelas hubungan antara variabel kepemimpinan, motivasi, iklim organisasi, dan kinerja karyawan, serta diharapkan hasil dari penelitian ini dapat menjadi referensi bagi peneliti lainnya yang melakukan penelitian dengan objek yang sama, kegunaan secara praktis darihasil penelitian ini diharapkan memberikan kontribusi pemikiran bagi pihak perusahaan tentang informasi yang berkaitan mengenai kepemimpinan, motivasi, kinerja karyawan, dan iklim organisasi. Kepemimpinan yang baik akan mampu memberikan hubungan timbal balik yang selaras dan harmonis dalam menghasilkan tujuan bersama menuju kejenjang yang lebih tinggi, sesuai dengan keinginan yang akan dicapainya (Prajadi, 2014).

Teori Motivasi yang digunakan di dalam penelitian ini adalah Teori ERG (Exsistence, Relatedness, Growth) diman teori ini yang mengelompokkan kebutuhan manusia adalah sebagai berikut (Prajadi, 2014). Relatedness needs (kebutuhan hubungan sosial) kebutuhan ini merupakan kebutuhan interpersonal, yaitu berinteraksi dan kepuasan dalam lingkungan kerja,growth needs (kebutuhan pertumbuhan) kebutuhan untuk mengembangkan diri dan meningkatkan pribadi, hal ini berhubungan dengan kecakapan dan kemampuan pegawai Existence needs (kebutuhan eksistensi kebutuhan ini berhubungan dengan fisik dari eksistensi pegawai, seperti minum, makan, gaji, bernafas, keamanan kondisi kerja,).

Hasil penelitian yang dilakukan oleh Prijati (2013), yang berjudul Pengaruh Gaya Kepemimpinan Terhadap Kinerja Karyawan Pada Rumah Sakit Siti Khodijah Sidoarjo dengan mengunakan sampel yang berjumlah 63 orang yang dimana menunjukkan positif dan signifikan. Penelitian yang dilakukan oleh 
Mehrabi (2012), Roozbehani (2012), Naseri (2012), dan Samangooei (2012) mengungkapkan bahwa ada hubungan yang signifikan dan positif antara pengembangan kepemimpinan dan dimensinya dengan kinerja karyawan. $\mathrm{H}_{1}$ : Kepemimpinan berpengaruh positif terhadap kinerja karyawan.

Hasil penelitian yang dilakukan oleh Ariffin (2014), yang berjudul Pengaruh Budaya Organisasi Dan Motivasi Terhadap Kinerja Pegawai Frontliner, (Studi Pada Cabang Bank Kalsel Yang Berada Di Wilayah Banjarmasin) Motivasi berpengaruh secara signifikan terhadap kinerja pegawai frontliner. Penelitian yang dilakukan oleh Ayesha Javed (2014, Irum Shahzadi (2014) ), Shagufta Nasreen (2014), Syed Shahzaib Pirzada(2014), dan Farida Khanam (2014).

$\mathrm{H}_{2}$ : Motivasi berpengaruh positif terhadap kinerja karyawan.

Berdasarkan penelitian yang dilakukan oleh Kiki (2015), dengan sampel penelitian adalah sebanyak 250 karyawan yang dimana terdapat pengaruh yang signifikan dari iklim organisasi Pada kinerja pada karyawan di Divisi Operasi PT. Palembang.Pusri Penelitian yang dilakukan oleh Githinji (2017) dan Gachunga (2017) penelitian ini mengungkapkan bahwa variabel iklim organisasi terhadap kinerja karyawan secara statistik sangat kuat dan signifikan. Penelitian yang dilakukan oleh Kubendran (2013), Sampath (2013), Muthukumar (2013) memiliki Persepsi positif dan signifikan terhadap iklim organisasi dan kinerja karyawan.

$\mathrm{H}_{3}$ : Iklim organisasi berpengaruh positif terhadap kinerja karyawan. 


\section{METODE PENELITIAN}

Penelitian ini bersifat asosiatif kuantitatif yang bertujuan untuk mengetahui pengaruh atau hubungan antara dua variabel atau lebih (Sugiyono, 2013:55) dan, untuk meneliti data yang bersifat statistik serta menguji suatu hipotesis, dengan menggunakan kuesioner sebagai instrumen. Penelitian ini dilakukan untuk mengetahui pengaruh kepemimpinan, motivasi, iklim organisasi terhadap kinerja karyawan. Data yang diperoleh agar dapat membuktikan hipotesis dan menjawab rumusa masalah yang telah dibuat sebelumnya. Desain penelitian secara rinci dapat dilihat pada Tabel 3.1 sebagai berikut.

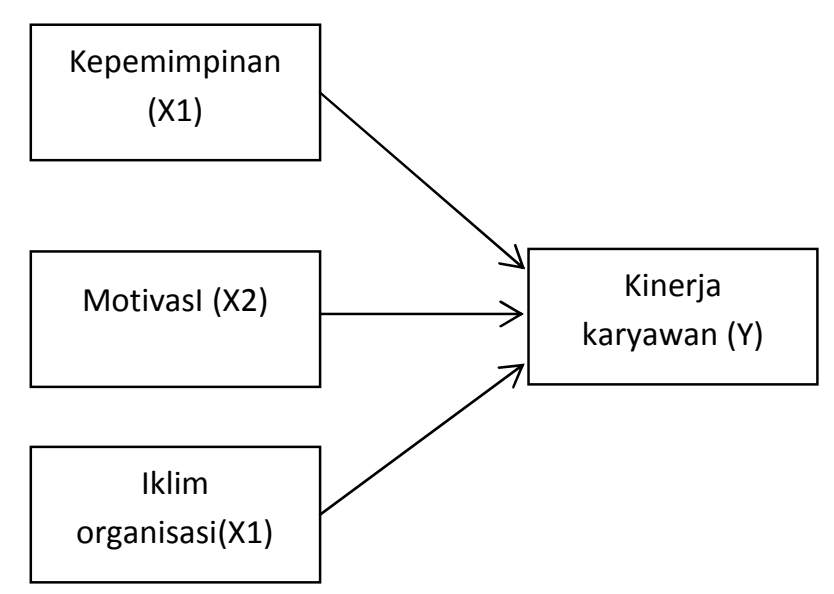

Gambar 1.Desain Penelitian

Objek penelitian yang digunakan dalam penelitian ini terkait dengan pengaruh kepemimpinan, motivasi, dan iklim organisasi terhadap kinerja karyawan di Warung Mina Peguyangan Denpasar Bali. Adapun berikut ini merupakan definisi variabel didalam penelitian ini adalah kepemimpinan, motivasi, iklim organisasi, dan kinerja karyawan. 
Populasi adalah wilayah generalisasi yang terdiri dari obyek atau subyek yang menjadi kualitas dan karakteristik tertentu yang ditetapkan oleh peneliti untuk di pelajari dan ditarik kesimpulannya (Sugiyono 2013;115). Populasi dari penelitian ini adalah keseluruhan karyawan Warung Mina Peguyangan. Mengingat jumlah sampel responden sebesar 44 orang sehingga layak untuk diambil keseluruhannya untuk dijadikan responden tanpa mengambil sampel dalam jumlah tertentu.

Adapun sampel yang digunakan dalam penelitian ini yaitu probability sampling meliputi, sampel random sampling di mana dikatakan sample (sederhana) karena pengambilan anggota sampel dari populasi di lakukan secara acak tanpa memperhatikan stara yang ada dalam populasi itu (Sugiyono 2013;118).Instrumen yang digunakan dalam penelitian ini berupa kuesioner yang terdiri atas sejumlah pernyataan mengenai variabel bebas yang terdiri atas kepemimpinan, motivasi, iklim organisasi dan variabel terikat, yaitu kinerja karyawan. Jawaban responden akan dinilai menggunakan skala Likert5 poin.

Uji validitas dilakukan dengan cara menghitung korelasi masing-masing skor pertanyaan atau pernyataan. Jika koefisien korelasi diatas 0,3 maka suatu instrumen dikatakan valid (Sugiyono, 2013:455). Uji validitas biasa menggunakan bantuan dari program SPSS (Statical Product and Service Solution).

Uji reliabilitas pada penelitian ini dilakukan dengan bantuan program SPSS.Suatu data dinyatakan reliabel apabila dua atau lebih peneliti dalam obyek yang sama menghasilkan data yang sama, atau peneliti sama dalam waktu yang berbeda menghasilkan data yang sama, atau sekelompok data bila dipecah 
menjadi dua menunjukkan data yang tidak berbeda. Suatu data yang reliabel atau konsisten akan cenderung valid, walaupun belum tentu valid (Sugiyono, 2013:456).

Teknik analisis data dalam penelitian ini dengan menggunakan teknik analisis linear berganda dimana analisis regresi ganda digunakan oleh peneliti, bila peneliti bermaksud meramalkan bagaimana keadaan (naik turunnya) variabel dependen (kriterium), bila dua atau lebih variabel independen sebagai faktor prediktor dimanipulasi (dinaik turunkan nilainnya) (Sugiyono 2013;277).

Persamaan regresi linear berganda penelitian adalah sebagai berikut:

$\mathrm{Y}=\alpha+\beta_{1} \mathrm{X}_{1}+\beta_{2} \mathrm{X}_{2}+\beta_{3} \mathrm{X}_{3}+\mathrm{e}$

Keterangan :

$\mathrm{Y}=$ Kinerja Karyawan

$\mathrm{X}_{1} \quad=$ Kepemimpinan

$\mathrm{X}_{2} \quad=$ Motivasi

$\mathrm{X}_{3} \quad=$ Iklim Organisasi

$\alpha \quad=$ Konstanta

$\beta_{1}, \beta_{2}, \beta_{3}=$ Koefisien Regresi Variabel Independen

$\mathrm{e} \quad=$ Error $/$ Variabel lain yang tidak teridentifikasi dalam model

Pengaruh variable dependen terhadap variable independen diuji dengan tingkat kepercayaan $95 \%$ atau $\alpha=5 \%$.

\section{HASIL DAN PEMBAHASAN}

Analisis regresi linier berganda digunakan untuk mencari koefisien regresi yang akan menentukan apakah hipotesis yang dibuat akan diterima atau ditolak. Analisis regresi linear berganda diolah dengan bantuan software SPSS versi 23 dengan hasil yang dapat dilihat pada Tabel 2 berikut.

$\beta_{1}=0,376$ berarti pengaruh kepemimpinan $\left(\mathrm{X}_{1}\right)$ mengakibatkan peningkatan kinerja karyawan (Y), dengan asumsi variabel bebas yang lain 
dianggap konstan. $\beta_{2}=0,786$ berarti pengaruh iklim organisasi $\left(\mathrm{X}_{2}\right)$ mengakibatkan peningkatan kinerja karyawan (Y), dengan asumsi variabel bebas yang lain dianggap konstan. $\beta_{3}=0,408$ berarti pengaruh iklim organisasi $\left(\mathrm{X}_{3}\right)$ mengakibatkan peningkatan kinerja karyawan $(\mathrm{Y})$, dengan asumsi variabel bebas yang lain dianggap konstan.

Tabel 2.

Hasil Analisis Regresi Linier Berganda

\begin{tabular}{|c|c|c|c|c|c|}
\hline \multirow[t]{2}{*}{ Model } & \multicolumn{2}{|c|}{$\begin{array}{c}\text { Unstandardized } \\
\text { Coefficients }\end{array}$} & \multirow{2}{*}{$\begin{array}{l}\text { Standardizd } \\
\text { Coefficients }\end{array}$} & \multirow[t]{2}{*}{$\mathrm{T}$} & \multirow[t]{2}{*}{ Sig. } \\
\hline & $\beta$ & Std. Error & & & \\
\hline (Constant) & 3,368 & 3,351 & & 1,005 & 0,321 \\
\hline Kepemimpinan & 0,376 & 0,151 & 0,280 & 2,498 & 0,017 \\
\hline Motivasi & 0,786 & 0,215 & 0,426 & 3,659 & 0,001 \\
\hline Iklim Organisasi & 0,408 & 0,171 & 0,277 & 2,393 & 0,021 \\
\hline R Square & & & & & \\
\hline F Hitung & & & & & \\
\hline Signifikansi $F=0,000$ & & & & & \\
\hline
\end{tabular}

Uji normalitas bertujuan untuk menguji apakah dalam residual dari model regresi yang dibuat berdistribusi normal ataukah tidak. Uji normalitas pada penelitian ini menggunakan uji Kolmogorov-Smirnov, data berdistribusi normal apabila koefisien Asymp.Sig. (2-tailed) lebih besar dari 0,05 ( $\alpha=5$ persen). Hasil uji normalitas dapat dilihat pada Tabel 3 sebagai berikut.

Tabel 3.

Hasil Uji Normalitas

\begin{tabular}{|c|c|}
\hline Keterangan & Unstandardized Residual \\
\hline $\mathrm{N}$ & 44 \\
\hline Kolmogorov-Smirnov $Z$ & 0,578 \\
\hline Asymp.Sig. (2-tailed) & 0,892 \\
\hline
\end{tabular}

Sumber:Datadiolah, 2018.

Berdasarkan Tabel 4 dapat dilihat bahwa nilai Kolmogorov-Smirnov $Z$ sebesar 0,578, sedangkan nilai Asymp.Sig. (2-tailed) sebesar 0,892. Hasil tersebut 
mengindikasikan bahwa model persamaan regresi tersebut berdistribusi normal karena nilai Asymp.Sig. (2-tailed) 0,578 lebih besar dari nilai alpha 0,05.

Uji Heteroskedastisitas bertujuan menguji apakah dalam model regresi terjadi ketidaksamaan varians dari residual satu pengamatan ke pengamatan lainnya. Jika tidak ada satupun variabel bebas yang berpengaruh signifikan terhadap nilai absolute residual atau nilai signifikansinya di atas 0,05 maka tidak mengandung gejala heteroskedastisitas. Hasil uji heteroskedastisitas dapat dilihat pada Tabel 4 sebagai berikut.

Tabel 4.

Hasil Uji Heteroskedastisitas

\begin{tabular}{|c|c|c|c|c|c|}
\hline \multirow[t]{2}{*}{ Model } & \multicolumn{2}{|c|}{$\begin{array}{c}\text { Unstandardized } \\
\text { Coefficients }\end{array}$} & \multirow{2}{*}{$\begin{array}{l}\text { Standardizd } \\
\text { Coefficients }\end{array}$} & \multirow[t]{2}{*}{$\mathrm{t}$} & \multirow[t]{2}{*}{ Sig. } \\
\hline & $\mathrm{B}$ & Std. Error & & & \\
\hline (Constant) & 3,221 & 1,985 & & 1,623 & ,113 \\
\hline Kepemimpinan & ,064 & ,089 & 130 & ,718 & ,477 \\
\hline Motivasi &,- 041 &, 127 &,- 061 &,- 323 & ,748 \\
\hline Iklim Organisasi &,- 119 & 101 &,- 221 & $-1,181$ & 244 \\
\hline
\end{tabular}

Berdasarkan Tabel 4 dapat dilihat bahwa nilai Sig. dari variabel kepemimpinan sebesar 0,477 , motivasi sebesar 0,748 dan iklim organisasi sebesar 0,244. Nilai tersebut lebih besar dari 0,05 yang berarti tidak terdapat pengaruh antara variabel bebas terhadap absolute residual. Dengan demikian, model yang dibuat tidak mengandung gejala heteroskedastisitas.

Uji multikolinieritas bertujuan untuk menguji apakah pada model regresi ditemukan adanya korelasi antar variabel bebas. Adanya multikolinieritas dapat dilihat dari nilai tolerance dan nilai variance inflation factor (VIF) dan bila nilai tolerance lebih dari 0,10 (10\%) atau VIF kurang dari 10, maka dikatakan tidak ada 
multikolinieritas. Hasil uji multikolinieritas dapat dilihat pada Tabel 5 sebagai berikut.

Tabel 5.

Hasil Uji Multikolinieritas

\begin{tabular}{lccc}
\hline & Variabel & Tolerance & VIF \\
\hline Kepemimpinan & 0,722 & 1,384 \\
Motivasi & 0,669 & 1,494 \\
Iklim organisasi & 0,678 & 1,476 \\
\hline
\end{tabular}

Sumber: Data diolah, 2018

Berdasarkan Tabel 5 apat dilihat bahwa nilai tolerance dan VIF dari variabel kepemimpinan, motivasi dan iklim organisasi. Nilai tersebut menunjukkan bahwa nilai tolerance untuk setiap variabel lebih besar dari $0,10(10 \%)$ dan nilai VIF lebih kecil dari 10 yang berarti model persamaan regresi bebas dari multikolinieritas.

Hasil uji $\mathrm{F}$ dapat dijelaskan dengan nilai signifikan annova $<\alpha=0,05$ maka model ini dikatakan layak atau variabel bebas mampu menjelaskan variabel terikat. Hasil uji F dapat dilihat pada Table 6 sebagai berikut.

Tabel 6.

Hasil Uji F

\begin{tabular}{lccccc}
\hline \multicolumn{1}{c}{ Model } & $\begin{array}{c}\text { Sum of } \\
\text { Squares }\end{array}$ & Df & Mean Square & F & Sig. \\
\hline Regression & 250,961 & 3 & 83,654 & 23,453 & 0,000 \\
Residual & 142,675 & 40 & 3,567 & & \\
Total & 393,636 & 43 & & & \\
\hline
\end{tabular}

Sumber: Data diolah, 2018

Berdasarkan Tabel 6 menunjukkan nilai signifikan sebesar 0,000 yang lebih kecil dari nilai $\alpha=0,05$ maka model regresi linier berganda layak digunakan sebagai alat analisis untuk menguji pengaruh variabel bebas terhadap variabel terikat. 
Hasil uji koefisien determinasi $\left(\mathrm{R}^{2}\right)$ dapat dilihat pada Tabel 7 sebagai berikut.

Tabel 7.

Hasil Uji Koefisien Determinasi $\left(\mathbf{R}^{2}\right)$

\begin{tabular}{cccc}
\hline $\mathrm{R}$ & $R$ Square & Adjusted $R$ Square & $\begin{array}{c}\text { Std Error of the } \\
\text { Estimate }\end{array}$ \\
\hline 0,798 & 0,638 & 0,610 & 1,889 \\
\hline Sumber: Data diolah, 2018. & & &
\end{tabular}

Berdasarkan Tabel 7 ilai $R$ Square adalah 0,638 yang artinya 63,8 persen kinerja karyawan di Warung Mina Peguyangandipengaruhi oleh kepemimpinan, mativasi dan iklim organisasi yang diterapkan di perusahaan, sedangkan sisanya 36,2 persen dijelaskan oleh faktor lain yang tidak dijelaskan dalam penelitian ini.

Uji hipotesis yang diuji menggunakan uji parsial (uji t) untuk menguji pengaruh masing-masing variabel bebas, yaitu kepemimpinan, motivasi dan iklim organisasi terhadap variabel terikat kinerja karyawan. Tabel 8 menunjukkan hasil perhitungan uji hipotesis adalah sebagai berikut.

Tabel 8.

\section{Hasil Uji t}

\begin{tabular}{lccc}
\hline Variabel & & $\mathrm{t}$ & sig. \\
\hline Kepemimpinan & $\mathrm{X}_{1}$ & 2,498 & 0,017 \\
Motivasi & $\mathrm{X}_{2}$ & 3,659 & 0,001 \\
Iklim organisasi & $\mathrm{X}_{3}$ & 2,393 & 0,021 \\
\hline \multicolumn{2}{l}{ Sumber: Data diolah, 2018. } & &
\end{tabular}

Jika Sig. $\mathrm{t}<0.05$ maka $\mathrm{H}_{0}$ ditolak dan $\mathrm{H}_{1}$ diterima.Jika Sig. $\mathrm{t}>0.05$ maka $\mathrm{H}_{0}$ diterima dan $\mathrm{H}_{1}$ ditolak.

Hasil penelitian menunjukkan bahwa kepemimpinan berpengaruh positif dan signifikan terhadap kinerja karyawan yang berarti apabila kepemimpinan semakin baik maka kinerja karyawan di Restoran Warung Mina Peguyanganakan 
meningkatdan sebaliknya, semakin buruk kepemimpinan yang dimiliki di Restoran Warung Mina Peguyangan maka kinerja karyawanakan menurun. Hasil penelitian ini sesuai dengan penelitian sebelumnya yang Penelitian yang dilakukan oleh Mehrabi (2012), Roozbehani (2012), Naseri (2012), dan Samangooei (2012) mengungkapkan bahwa ada hubungan yang signifikan dan positif antara pengembangan kepemimpinan dan dimensinya dengan kinerja karyawan.

Hasil penelitian menunjukkan bahwa motivasi berpengaruh positif dan signifikan terhadap kinerja karyawan yang berarti apabila motivasi kirja semakin baik maka kinerja karyawan di Restoran Warung Mina Peguyanganakan meningkatdan sebaliknya, semakin buruk motivasi kerja maka kinerja karyawan di Restoran Warung Mina Peguyanganakan menurun. Hasil penelitian ini sesuai dengan penelitian sebelumnya yang dilakukan oleh Javed (2014), Shahzadi (2014) , Nasreen (2014), Pirzada (2014), dan Khanam (2014) Hasil penelitian ini menunjukkan bahwa signifikan dan positif hubungan antara motivasi kerja dengan karyawan.

Hasil penelitian menunjukkan bahwa iklim organisasi berpengaruh positif dan signifikan terhadap kinerja karyawan yang berarti apabila iklim organisasi di Restoran Warung Mina Peguyangan semakin baik maka kinerja karyawan di Restoran Warung Mina Peguyanganakan meningkatdan sebaliknya, semakin buruk iklim oraganisasi di Restoran Warung Mina Peguyangan maka kinerja karyawan di Restoran Warung Mina Peguyanganakan menurun. Hasil penelitian ini sesuai dengan penelitian sebelumnya yang dilakukan oleh Githinji (2017) dan 
Gachunga (2017) penelitian ini mengungkapkan bahwa variabel iklim organisasi terhadap kinerja karyawan secara statistik sangat kuat dan signifikan.

Implikasi penelitian ini menekankan pada manfaat dari hasil penelitian yang dapat dijadikan sebagai strategi untuk menciptakan kinerja karyawan yang baik pada Restoran Warung Mina Peguyangan. Berikut beberapa implikasi dari hasil penelitian ini, yaitu :Kepemimpinan berpengaruh positif dan signifikan terhadap kinerja karyawan. Hasil ini berarti pimpinan perusahaan diharapkan dapat memperhatikan kerjasama hubungan kerja antara karyawan maupun hubungan kerja dengan atasan sehingga akan tercipta tim kerja yang baik. Hal ini dapat dilakukan dengan menjalin komunikasi yang baik sehingga akan tercipta hubungan kerja yang harmonis dan pada akhirnya dapat meningkatkan kinerja karyawan. Motivasi berpengaruh positif dan signifikan terhadap kinerja karyawan. Hasil ini berarti dengan adanya motivasi yang baik terhadap kinerja karyawan di Restoran Warung Mina Peguyangan pada akhirnya akan mampu meningkatkan kinerja karyawan. Hasil ini berarti jika kinerja karyawan dapat tercipta dengan cara memberikan penghargaan terhadap karyawan yang telah bekerja dengan baik sehingga memberikan rasa puas terhadap karyawan yang telah bekerja dengan baik dan karyawan tersebut akan semangat bekerja dan merasa nyaman bekerja di perusahaan. Iklim organisasi berpengaruh positif dan signifikan terhadap kinerja karyawan. Hasil ini berarti dengan menerapkan iklim organisasi dengan baik pada akhirnya akan mampu meningkatkan kinerja karyawan. Manajemen diharapkan dapat memperlakukan setiap karyawan dengan adil sehingga tidak akan timbul 
kecemburuan sosial antar karyawan dan pada akhirnya dapat meningkatkan kinerja karyawan.

\section{SIMPULAN}

Berdasarkan hasil penelitian dan pembahasan di atas, dapat ditarik beberapa simpulan, antara lain sebagai berikut. Kepemimpinan berpengaruh positif dan signifikan terhadap kinerja karyawan di Restoran Warung Mina Peguyangan. Hal ini menunjukkan semakin baik kepemimpinan di Restoran Warung Mina Peguyangan maka kinerja karyawan di Restoran Warung Mina Peguyangan akan meningkat. Motivasi berpengaruh positif dan signifikan terhadap kinerja karyawan di Restoran Warung Mina Peguyangan. Hal ini menunjukkan semakin baik motivasi kerja pada karyawandi Restoran Warung Mina Peguyangan maka kinerja karyawan di Restoran Warung Mina Peguyangan juga akan meningkat. Iklim organisasi berpengaruh positif dan signifikan terhadap kinerja karyawan di Restoran Warung Mina Peguyangan. Hal ini menunjukkan semakin baik iklim organisasi di Restoran Warung Mina Peguyangan maka kinerja karyawan di Restoran Warung Mina Peguyangan juga akan meningkat.

Saran yang dapat peneliti usulkan berdasarkan hasil penelitian dan simpulan yang telah diuraikan di atas adalah sebagai berikut. Manajemen Restoran Warung Mina Peguyangandiharapkan dapat memperhatikan hubungan interpersonel karyawan, yaitu kerjasama yang baik antara manajemen dengan karyawan. Manajemen dapat menjaga komunikasi dan lebih sering mengadakan kegiatan bersama para karyawan seperti kegiatan team building dan outbound. Yang 
nantinya akan membuat para karyawan akan semakin akrab dengan pimpinan dan juga semakin akrab dengan sesama rekan kerja. Manajemen Restoran Warung Mina Peguyangan dapat meningkatkan pengawasan menyeluruh terhadap pekerjaan karyawan, memberikan upah sesuai dengan beban kerja, memberikan kesempatan untuk mendapatkan jalur karir yang jelas dan memastikan hubungan antar rekan kerja terjalin baik sehingga dengan hal tersebut karyawan akan merasa puas berada di perusahaan. Peneliti selanjutnya yang melakukan penelitian serupa dapat memperluas cakupan lokasi dan diharapkan untuk mengkaji lebih banyak sumber maupun referensi serta mempertimbangkan variable-variabel lain yang dapat mempengaruhi kinerja karyawan.

\section{REFERENSI}

Acar, A.Z. (2012). Organizational culture, leadership styles and organizational commitment in Turkish logistics industry. International JournalStrategic Management Conference, 58(12), 217-226.

Aniek, W. (2017). Pengaruh Motivasi Kerja dan Lingkungan Kerja Terhadap Kinerja Karyawan Medis. Jurnal Ilmu dan Riset Manajemen, 6(5), 77-89.

Anum, K., Muhammad Ramzan dan Muhammad Saqib Butt. (2013). Is Job Satisfaction Of Islamic Banks Operational Staff Determined Through Organizational Climate, Occupational Stress, Age and Gender. Journal of Business Studies Quarterly, 4(3), 1-9.

Arrizqi, Mochamad Fanny, Hamidah Nayati Utami dan Arik Prasetya. (2015). Faktor-faktor Pendorong Partisipasi Karyawan Dalam Pelaksanaan Penilaian Kinerja Karyawan (Studi pada PT. PLN (Persero) Distribusi Jawa Timur Area Malang). Jurnal Administrasi Bisnis, 27(2), 8-15.

Asri, W.S. dan Endang, S. (2016). Iklim Organisasi Dan Motivasi Kerja Sebagai Diterminan Kinerja Pegawai"Organizational Climate and Work Motivation as Determinants of Employees Performance”. Jurnal pendidikan manajemen perkantoran, 1(1), 19-29. 
Bangun Prajadi. (2014). Pengaruh Kepemimpinan, Motivasi Kerja, Disiplin Kerja dan Lingkungan Kerja Terhadap Kinerja Karyawan dan Dosen Stmik Duta Bangsa Surakarta. Jurnal Sainstech Politeknik Indonusa Surakarta, 1(1), 2340 .

Brahmana dan Sofyandi, (2009).Pengaruh Iklim Organisasi dan Komitmen Organisasi Terhadap Pembentukan Organizational Citizenship Behavior (Ocb)Karyawan Dalam Rangka Peningkatan Kinerja.E-Jurnal Apresiasi Ekonomi, 1(2), 75-85.

Cheng Kang Yuan dan Lee Chuan Yin. (2011). Exploration of a construct model linking leadership types, organization culture, employees performance and leadership performance. International Journal Conference on Asia Pacific Business Innovation \& Technology Management, 25(1), 123-136.

Delti. (2015). Pengaruh Kepemimpinan Terhadap Kinerja Karyawan Pada Pt. Trubaindo Coal Mining di Kabupaten Kutai Barat. E-Jurnal Ilmu Administrasi Bisnis, 3(2), 495-506.

Fauziah Noordin, Safiah Omar, Syakirarohan Sehan dan Shukriah Idrus. (2010). Organizational Climate And Its Influence On Organizational Commitment.International Journal Business \& Economics Research Journal, 9(2), 1-5.

Ghani, N.M.A., N.S. Nadia Muhamad Yunus dan Norliza Saiful Bahry. (2016). Leader's Personality Traits and Employees Job Performance in Public Sector, Putrajaya. JournalFaculty of Business and Management, 37(1), 46-51.

Harry M. dan Veronika A.S. (2013). Pengaruh Motivasi Terhadap Kinerja Pegawai Dengan Variabel Pemediasi Kepuasan Pada PDAM Kota Madiun. Jurnal Riset Manajemen dan Akuntansi, 1(1), 10-17.

Hasan Tutar, Mehmet Altinoz dan Demet Cakiroglu. (2011). The effects of employee empowerment on achievement motivation and the contextual performance of employees.African Journal of Business Management, 5(15), 6318-6329..

Hashim Z. dan Shehzad A. (2014). The Impact of the Motivation on the Employee's Performance in Beverage Industry of Pakistan. Journal Finance and Management Sciences, 4(1), 293-298.

Jaroslav Belas. (2013). The Leadership Style and the Productiveness of Employees in the Banking Sector in Slovakia. Journal of Competitiveness, 5(1), 39-52. 
Kiswanto, M. (2010). Pengaruh Kepemimpinan dan Komunikasi Terhadapkinerja Karyawan Kaltim Pos Samarinda. Jurnal Eksis, 6(1), 1429-1439.

Kubendran, V., M. Sampath Nagi dan Muthukumar S. (2013). Organisational climate's impact on employee's performance. Indian Journal of Economics and Development, 1(3), 2320-9839.

Lubis, M.S. (2015). Pengaruh Iklim Organisasi Dan Komitmen Organisasi Terhadap Pembentukan Organizational Citizenship Behavior (Ocb) Karyawan Dalam Rangka Peningkatan Kinerja.E-Jurnal Apresiasi Ekonomi, $3(2), 75-48$.

Malian, M. (2015). Pengaruh Motivasi Terhadap Kinerja Pegawai Pada PT. PLN (Persero) Rayon Pangkalan Balai. Jurnal Media Wahana Ekonomika, 12(2), 28-31.

Marthis, Robert L. dan John H. Jackson. (2006). Manajemen Sumber Daya Manusia. Edisi Pertama. Jakarta: Salemba Empat.

Mehrabi Javad, Mohammad T. Roozbehani, Shirin Naseri dan Batool Samangooei. (2012). Impact of Leadership Development on Employees' Performance. International Journal of Business, Humanities and Technology, 2(5), 20-29.

Mei Teh, G. (2014). Impact of Organizational Climate on Intentions to Leave and Job Satisfaction. World Journal of Management, 5(2), 1-20.

Muogbo dan Uju S. (2013). The Influence of Motivation on Employees Performance: A Study of Some Selected Firms in Anambra State. International Journal of Arts and Humanities Bahir Dar, Ethiopia, 2(3), 1-7.

Naomi, W., Githinji dan Hazel Gachunga. (2017). Influence Of Organizational Climate On Employee Performance In State Corporations In Kenya: A Case Of Kenya Industrial Estates Limited. Journal of Business \& Change Management, 4(2), 376-395.

Nita, R.S., Moehammad S. Hakam dan Heru Susilo. (2015). Pengaruh kepuasan kerja terhadap turnover intention (Studi pada AJB Bumiputera 1912 Kantor Wilayah Jatim II/Malang). Jurnal Administrasi Bisnis (JAB), 27(1), 10-47.

Pamela Akinyi Omollo. (2015). Effect of motivation on employee performance of commercial banks in Kenya: A case study of Kenya Commercial Bank in Migori County. International Journal of Human Resource Studies, 5(2), 1-30. 
Ridwan, I.L., Heru Susilo dan Muhammad Faisal Riza. (2014). Pengaruh Motivasi Terhadap Kinerja Karyawan (Studi Pada Pt Elsiscom Prima Karya, Kantor Perwakilan Surabaya).Jurnal Administrasi Bisnis (JAB), 13(1), 67-87.

Shahzadi Irum, Ayesha Javed, Syed Shahzaib Pirzada, Shagufta Nasreen dan Farida Khanam. (2014). Impact of Employee Motivation on Employee Performance. European Journal of Business and Management, 6(23), 159166.

Sutrischastini. (2015).Pengaruh Motivasi Kerja Terhadap Kinerja Pegawai Kantor Sekretariat Daerah Kabupaten Gunung kidul.Jurnal Kajian Bisnis, 23(2), 411.

Surbakti. (2013). Analisis Pengaruh Kepemimpinan Transformasional dan Motivasi terhadap Kinerja Karyawan: Studi pada PT. Kereta Api Indonesia Daop IV Semarang. Jurnal Fakultas Ekonomi Universitas Diponegoro Semarang, 1(1), 55-67.

Toulson \& Smith, (2011).Pengaruh Iklim Organisasi Dan Komitmen Organisasi Terhadap Pembentukan Organizational Citizenship Behavior (Ocb) Karyawan Dalam Rangka Peningkatan Kinerja.E-Jurnal Apresiasi Ekonomi, $3(2), 120-133$.

Wilson Lisan, Jantje Sepang dan Greis Sendow. (2016). Analisis Pengaruh Turnover Karyawan, Motivasi, Dan Pengayaan Pekerjaan, Terhadap Kepuasan Kerja Karyawan Pada Pt. Enseval Megatrading Tbk Manado. Jurnal Berkala Ilmiah Efisiensi, 16(3), 47-55.

Wirawan. (2008). Pengaruh Kepemimpinan dan Iklim Organisasi Terhadap Kinerja Pegawai Pada UPTD Pengembangan Produktivitas Daerah Disnakertrans Provinsi Kalimantan Timur. E-Jurnal Administrative Reform, $1(3), 5-15$.

Yehezkiel, Masjaya dan Rosa A. (2013). Pengaruh Kepemimpinan dan Iklim Organisasi Terhadap Kinerja Pegawai Pada UPTD Pengembangan Produktivitas Daerah Disnakertrans Provinsi Kalimantan Timur. E-Jurnal Administrative Reform, 1(3), 1-20. 